\title{
АССОЦИАЦИЯ SNP ГЕНОВ БЕЛКОВ УРОКИНАЗНОЙ СИСТЕМЫ С РАЗВИТИЕМ ПЛАЦЕНТАРНОЙ НЕДОСТАТОЧНОСТИ
}

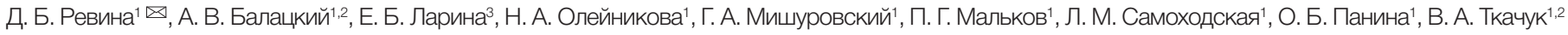

${ }_{1}^{1}$ Московский государственный университет имени М. В. Ломоносова, Москва, Россия

2 Национальный медицинский исследоваельский центр кардиологии, Москва, Россия

${ }^{3}$ Клинический госпиталь Лапино «Мать и дитя», Москва, Россия

Плацентарная недостаточность (ПН) и ее осложнения - многофакторные заболевания, ведущие к перинатальной заболеваемости и смертности Урокиназная система задействована в формировании плаценты и может быть рассмотрена как участник патогенеза ПН. Целью работы было исследовать ассоциацию однонуклеотидных полиморфизмов (SNP) генов белков урокиназной системы с развитием ПН, их влияние на экспрессию соответствующих белков в плаценте и ее строение. Обследованы 114 женщин с физиологическим течением беременности и родов и 48 пациенток с преэклампсией и/или задержкой роста плода (ЗРП), 95 новорожденных детей (беременность с преэклампсией и/или ЗРП - 60, физиологическое течение беременности и родов - 35). Проведено генотипирование при помощи ПЦР в реальном времени, морфометрическое и иммуногистохимическое исследования фрагментов плацент. Выявлены ассоциации между развитием ПН и наличием у матери - аллеля C rs 4065 (в группе ПН - CC-CT 64,1\%, ПТ 35,9\%, в контрольной группе - CC-СТ 25,6\%, Т 74,49\%, ОШ (95\% ДИ) - 6,83 (2,63-17,79)), аллеля A rs2302524 (GG-GA 20,5\%, AA 79,5\% против GG-GA 48,1\%, AA 51,9\%, ОШ (95\% ДИ) - 0,27 (0,1-0,71)), у плода - аллеля C rs4065 (СС-СТ 76,4 \%, ПТ 23,6\% против СС-СТ 69,6\%, ПТ 30,4\%, ОШ (95\% ДИ) - 1,37 (0,45-4,17)), аллеля C rs344781 (Тт-ТС 69,1\%, CС 30,9\% против ТТ-ТС 95,7\%, СС 4,3\%, ОШ (95\% ДИ) - 5,02 (1,07-23,6)). Многофакторный анализ подтвердил значимость генотипа плода по rs4065. Экспрессия uРА была ниже при ПН (медиана (95\% ДИ) - 116,45 (100,5; 128,74) против 126,09 (113,76; 139,19); $p$ < 0,05). Ассоциации SNP с экспрессией белков выявлено не было. Васкуляризация зависела от генотипа матери по rs4065 (стромальнососудистое соотношение при генотипе СС - 0,17 (0,15; 0,19), СТ - 0,18 (0,15; 0,21), ТТ - 0,23 (0,2; 0,27); $p<0,05)$. Таким образом, высокий уровень UPA в плаценте и наличие генотипа rs4065 ПТ у плода носят протективный характер в отношении развития ПН.

Ключевые слова: преэклампсия, задержка роста плода, плацентарная недостаточность, активатор плазминогена урокиназного типа, рецептор активатора плазминогена урокиназного типа, однонуклеотидный полиморфизм, ангиогенез

Финансирование: исследование выполнено в рамках государственного задания МГУ имени М. В. Ломоносова и с использованием оборудования, приобретенного по программе научного развития МГУ имени М. В. Ломоносова.

Благодарности: ассистенту кафедры акушерства и гинекологии факультета фундаментальной медицины МГУ имени Ломоносова, к. М. Н. Николаю Назимовичу Мамедову за помощь в создании коллекции биоматериалов (фрагментов последов, образцов крови).

Информация о вкладе авторов: Д. Б. Ревина, А. В. Балацкий, Е. Б. Ларина, Л. М. Самоходская, О. Б. Панина и В. А. Ткачук - дизайн исследования: Д. Б. Ревина, А. В. Балацкий, Е. Б. Ларина, Н. А. Олейникова, Г. А. Мишуровский - сбор и обработка биоматериала, клинических данных; Д. Б. Ревина, А. В. Балацкий, Г. А. Мишуровский - статанализ; Д. Б. Ревина, А. В. Балацкий - интерпритация результатов; Д. Б. Ревина, А. В. Балацкий, Г. А. Мишуровский, Н. А. Олейникова - написание рукописи; П. Г. Мальков. Л. М. Самоходская, О. Б. Панина, В. А. Ткачук - редактирование рукописи. Вклады Д. Б. Ревиной и А. В. Балацкого равноценны.

Соблюдение этических стандартов: исследование одобрено этическим комитетом Медицинского научно-образовательного центра МгУ имени М. В. Ломоносова (протокол № 4 от 4 июня 2018 г.). Все пациенты подписали добровольное информированное согласие на включение в исследование.

$\bigotimes$ Для корреспонденции: Дарья Борисовна Ревина

Ломоносовский проспект, д. 27, корп. 1, г. Москва, 119192; lozinskaya.daria@gmail.com

Статья получена: 31.10.2019 Статья принята к печати: 18.11.2019 Опубликована онлайн: 07.12.2019

DOI: $10.24075 /$ vrgmu.2019.076

\section{ASSOCIATIONS BETWEEN SNPS IN THE GENES ENCODING UROKINASE SYSTEM PROTEINS AND THE RISK OF PLACENTAL INSUFFICIENCY}

Revina $\mathrm{DB}^{1} \otimes$, Balatskiy $\mathrm{AV}^{1,2}$, Larina EB ${ }^{3}$, Oleynikova NA¹, Mishurovsky GA ${ }^{1}$, Malkov PG ${ }^{1}$, Samokhodskaya LM¹, Panina OB ${ }^{1}$, Tkachuk VA ${ }^{1,2}$

${ }^{1}$ Lomonosov Moscow State University, Moscow, Russia

${ }^{2}$ National Medical Research Center of Cardiology, Moscow, Russia

${ }^{3}$ Lapino Clinical Hospital "Mother and Child", Moscow, Russia

Placental insufficiency (PI) and its complications are multifactorial conditions that cause perinatal morbidity and mortality. Since the urokinase system is involved in placentation, it should have a role in PI pathogenesis. The aim of this work was to study the associations between single nucleotide polymorphisms (SNPs) of genes coding for protein components of the urokinase system and PI, as well as investigate their effect on the expression of these proteins in the placenta and placental structure. We examined 114 women with uncomplicated pregnancy and delivery, 48 female patients with pre-eclampsia and/or intrauterine growth restriction (IUGR), and 95 newborns, (pre-eclampsia and/or IUGR: $n=60$; uncomplicated pregnancy and delivery: $n=35$ ). Maternal and fetal DNAs were genotyped using real-time PCR. Placenta fragments were subjected to morphometry and immunohistochemistry. We discovered the associations between PI and the maternal C allele of rs4065 (PI group: CC-CT 64.1\%, TT 35.9\%; controls: CC-CT 25.6\%, TT 74.49\%; OR (95\%Cl): 6.83 (2.63-17.79)), the maternal A allele of rs2302524 (GG-GA 20.5\%, AA 79.5\% vs. GG-GA 48.1\%, AA 51.9\%, OR (95\%Cl): 0.27 (0.1-0.71)), the fetal C allele of rs4065 (CC-CT 76.4 \%, Tा $23.6 \%$ vs. CC-CT 69.6\%, TT 30.4\%, OR (95\%Cl): 1.37 (0.45-4.17)), and the fetal C allele of rs344781 (TT-TC 69.1\%, CC 30.9\% vs. TT-TC 95.7\%, CC 4.3\%, OR (95\% Cl): 5.02 (1.07-23.6)). The multivariate analysis confirmed the significance of the fetal rs4065 genotype. In patients with PI, uPA expression was lower (ME (95\%Cl): 116.45 (100.5; 128.74 ) vs. 126.09 (113.76; 139.19); $p$ < 0.05). No associations were established between SNPs and protein expression. The degree of vascularization depended on the maternal rs4065 genotype (the stroma-to-vessel ratio for the CC genotype was $0.17(0.15 ; 0.19)$; for the CT genotype, $0.18(0.15 ; 0.21)$ and for the $\Pi$ genotype, $0.23(0.2 ; 0.27) ; p<0.05)$. We conclude that high placental UPA and the presence of the fetal $\pi \mathrm{rs} 4065$ genotype are protective against the risk of PI.

Keywords: pre-eclampsia, intrauterine growth restriction, placental insufficiency, urokinase-type plasminogen activator, urokinase-type plasminogen activator receptor, single nucleotide polymorphism, angiogenesis

Funding: this study was conducted under the state assignment for Lomonosov MSU using the equipment acquired as part of the Scientific Development Program of Lomonosov MSU.

Acknowledgement: the authors thank Mamedov NN, PhD Med, an Assistant Professor at the Department of Obstetrics and Gynecology (Faculty of Fundamental Medicine, Lomonosov MSU) for his help in creating the collection of biosamples (umbilical cord and placenta fragments, blood samples).

Author contribution: Revina DB, Balatskiy AV, Larina EB, Samokhodskaya LM, Panina OB, Tkachuk VA — study design; Revina DB, Balatskiy AV, Larina EB, Oleynikova NA, Mishurovsky GA — collection and processing of biosamples and clinical datal; Revina DB, Balatskiy AV, Mishurovsky GA — statistical analysis; Revina DB, Balatskiy AV - interpretation of the results; Revina DB, Balatskiy AV, Oleynikova NA, Mishurovsky GA - manuscript preparation; Malkov PG, Samokhodskaya LM, Panina OB, Tkachuk VA — manuscript revision; Revina DB and Balatskiy AV equally contributed to the study.

Compliance with ethical standards: the study was approved by the Ethics Committee of Lomonosov MSU (Protocol 4 dated June 4 2018). All patients gave informed consent to participate.

$\square$ Correspondence should be addressed: Daria B. Revina

Lomonosovsky prospect, 27, k.1, Moscow, 119192; lozinskaya.daria@gmail.com

Received: 31.10.2019 Accepted: 18.11.2019 Published online: 07.12.2019

DOI: 10.24075/brsmu.2019.076 
Плацентарная недостаточность (ПН) и связанные с ней осложнения беременности (задержка роста плода (ЗРП) и преэклампсия) являются клиническим проявлением патологии плацентарного кровообращения. Патогенез ПН основан на нарушениях ангиогенеза в плаценте и аномалии созревания ворсинчатого древа, которые обусловлены рядом патологических процессов: 1) неполноценной инвазией трофобласта; 2) отсутствием ремоделирования спиральных артерий; 3) дисбалансом про- и антиангиогенных факторов; 4) изменениями реологических свойств крови матери [1]. Таким образом, особое внимание при изучении этиологии ПН следует обращать на многофрункциональные регуляторные системы, потенциально задействованные на каждом этапе формирования синдрома. К ним относится система урокиназы (активатор плазминогена урокиназного типа, UPA), состоящая из самого урокиназного активатора плазминогена, ее основного субстрата - плазминогена, ингибиторов активатора (PAI-1, PAl-2), а также рецептора урокиназы (UPAR), при условии взаимодействия с которым протеолиз, опосредованный урокиназой, происходит более эффективно [2]. Урокиназный комплекс, благодаря возможности запускать различные сигнальные каскады, способен не только изменять клеточное окружение путем протеолиза внеклеточного матрикса, но и инициировать в ответ на эти изменения процессы миграции и пролиферации клеток [3].

Почти все белки урокиназной системы имеют в своих генах полиморфные маркеры, влияющие на активность фермента или уровень его экспрессии, и для некоторых из них уже накоплены данные, подтверждающие их роль в развитии акушерской патологии. С точки зрения связи генетической вариабельности и клинических проявлений ПН из всех белков урокиназной системы наиболее изучен PAl-1. Уже доказана ассоциация инсерционноделеционной мутации в промотере -675 5G/4G SERPINE1 с невынашиванием беременности, преэклампсией $[4,5]$.

В меньшей степени изучен полиморфизм гена урокиназы и ее рецептора. В настоящей работе были выбраны две однонуклеотидные замены в гене PLAU (rs2227564, rs4065) и две - в гене PLAUR (rs344781, rs2302524) для исследования связи между ними и развитием ПН. Полиморфизм гена PLAU rs4065 C/T 3'UTR - замена C/T в некодирующей области, приводящая к изменению уровня UРА за счет увеличения стабильности мPHK [6]. Полиморфизм гена PLAU rs2227564 Pro141Leu обусловливает увеличение гидрофобности крингл-домена, что приводит к снижению афинности к фибрину и, возможно, компонентам внеклеточного матрикса [7]. Хотя роль крингл-домена урокиназы не до конца ясна, данный полиморфизм может оказывать влияние на ее активность. Полиморфизм PLAUR rs2302524 (A659G) также представляет собой миссенс-мутацию и потенциально может оказывать влияние на активность урокиназной системы [8]. Полиморфизм PLAUR rs344781 отражается на активности промотера гена, причем аллель Т приводит к усилению экспрессии [9]. Учитывая необходимость оценки как материнского, так и плодового компонентов системы «мать-плацента-плод», был исследован и генотип матери, и генотип плода. Данные генотипирования впоследствии были соотнесены с результатами гистологического исследования микропрепаратов плацент с целью оценки влияния полиморфизмов на морфометрические показатели и экспрессию соответствующих белков. Таким образом, целью работы было исследовать ассоциацию SNP генов белков UPA-uPAR-системы с развитием ПН, их влияние на интенсивность иммуногистохимической экспрессии соответствующих белков в плаценте и ее строение.

\section{ПАЦИЕНТЫ И МЕТОДЫ}

Исследование проводили в 2018 г. в Медицинском научнообразовательном центре МГУ имени М. В. Ломоносова. Образцы венозной крови, ткани плаценты, пуповины и клинические данные были получены из биобанка Медицинского научно-образовательного центра МГУ имени М. В. Ломоносова. Перечисленный материал был собран у 162 пациенток (20-49 лет) и 95 новорожденных детей непосредственно после завершения родов.

Контрольную группу составили 114 здоровых женщин. Критерии включения в контрольную группу: физиологическое течение беременности и родов. В группу ПН включили 48 пациенток. Критерии включения в группу ПН: ранняя преэклампсия (до 34 недель гестации) и/или ранняя ЗРП (до 32 недель) II-III степени. Диагноз ЗРП ІІ-ІІІ степени устанавливали при отставании фетометрических показателей более чем на 2 недели от фрактического срока гестации, определенного по первому дню последней менструации и ранним УЗИ. Диагноз преэклампсии был установлен при уровне систолического АД $\geq 140$ мм рт. ст. и диастолического АД $\geq 90$ мм рт. ст., зафиксированном не менее 2 раз после 20-й недели, и наличии одного и более следующих признаков: протеинурии $\geq 300$ мг/сут., почечного повреждения (гиперкреатиниемии $\geq 90$ мкмоль/л), нарушения функции печени (АЛТ или АСТ > 40 МЕ/л), нарушения кровотока в системе мать-плацента-плод по данным допплерометрии, тромбоцитопении < 150 000/мкл, неврологических симптомов. Критерии исключения пациенток из исследования: наличие многоплодной беременности; Rh-сенсибилизация; гестационный сахарный диабет, тяжелая экстрагенитальная патология; наркомания; табакокурение; пороки развития и генетические аномалии плода. Все беременности наступили самопроизвольно. С целью исключения феномена конституционально маленького плода (small for gestational age) проводили допплерометрию кровотока в артерии пуповины, из исследования были исключены пациентки с нормальными характеристиками кровотока.

Образцы пуповины были получены от 60 новорожденных детей группы ПН (беременность матери была осложнена преэклампсией и/или ЗРП), и от 35 новорожденных контрольной группы (с фризиологическим течением беременности и родов). Для анализа отбирали фрагмент пуповины на расстоянии 8-10 см от плаценты и фиксировали в 10\%-м формалине или замораживали при $-80{ }^{\circ} \mathrm{C}$. В 53 случаях были отобраны и образец крови матери, и фрагмент пуповины новорожденного, и ткань плаценты (25 случаев с ПН, 28 случаев из контрольной группы). Для каждой пары мать-новорожденный собирали по три фрагмента ткани плаценты размерами 1 × 0,5 × 0,5 cм из краевой, парацентральной и центральной зон визуально неизмененной плаценты; фрагменты фиксировали 10\%м забуференным раствором формальдегида в течение 12 ч, далее осуществляли гистологическую проводку и заливку в парафиновые блоки. Роды всех пациенток, для которых проводили гистологическое исследование плаценты, происходили путем операции кесарева сечения на сроке от 28 недель в группе ПН (2 пациентки - до 34-й недели, 6 - после 34-й недели), на доношенном сроке - в контрольной группе. 


\section{Генотипирование}

Выделение ДНК из цельной периферической крови матери с консервантом ЭДТА $\mathrm{K}_{2}$ проводили с помощью набора «QIAmp DNA Blood Mini Kit», из ткани пуповины - при помощи набора «DNeasy Blood and Tissue Kit» (QIAGEN; Германия) по стандартной методике, рекомендованной производителем (с минимальной массой образца пуповины 25 мг и пролонгированным лизисом в течение ночи).

Определение полиморфизмов C/T 3'-UTR (rs4065) гена PLAU и T(-516)C (rs344781) гена PLAUR проводили при помощи ПЦР с детекцией в реальном времени. Амплификацию осуществляли в детектирующем термоциклере «RotorGene Q» (QIAGEN; Германия). Применяли аллельспецифичные гидролизуемые зонды. Праймеры и зонды: rs4065 F: 5'-TGGTTGTCATIITGCAGTAGAGTC-3'; rs4065_R: 5'-GGCCTATGCCTGAGGGTAAAG-3'; rs4065_prC: FAM-5'-AAGCTATTGTCGTTCGCCCTGGTGG3'-BHQ1;

rs4065_prT: HEX-5'-AAGCTATTGTCGTTCACCCTGGTGGG3'-BHQ1;

rs344781_F: 5'-ATCCTGAAATATGCATCTCTTAAACACT-3'; rs344781_R: 5'-TTAACATTTACCAAGGACCTACTTCG-3'; rs344781_prC:FAM-5'-CACAGCGGGAAGCAAAGCAAGGGT3'-BHQ1;

rs344781_prT:HEX-5'-CACAGCAGGAAGCAAAGCAAGGGT3'-BHQ1).

Определение C/T 7240 (rs2227564) гена PLAU, A659G (rs2302524) гена PLAUR, -675 5G/4G SERPINE1 проводили при помощи ПЦР с детекцией в реальном времени и готовых наборов для определения SNP («ДНК-Технология»; Россия).

\section{Морфометрическое и}

\section{иммуногистохимическое исследования}

Из парафиновых блоков изготавливали срезы 4 мкм, которые затем монтировали на предметные стекла с адгезивным покрытием «Polysine Slides» (Menzel GmbH \& Co KG; Германия). Депарафинирование, регидратацию и демаскировку антигенов проводили при помощи буфрера «Dewaxand HIER BufferM» (pH 8,0) (Thermo; Великобритания) при температуре $95-98{ }^{\circ} \mathrm{C}$, в течение 20 мин в модуле предобработки К «РT-Module» (Thermo; Великобритания). Иммуногистохимические реакции проводили в автоматизированном режиме с помощью автостейнера «Thermo Scientific LabVision Autostainer 480S» (Thermo; Великобритания). Для проведения иммуногистохимического исследования использовали кроличьи моноклональные антитела к урокиназе (ab133563) в разведении 1: 150 и кроличьи поликлональные антитела к рецептору урокиназы (ab103791) в разведении 1: 100 (Abcam; Великобритания), время инкубации - 30 мин. В качестве системы детекции применяли систему «Ultra Vision Quanto Detection System» (Thermo; Великобритания) c DAB-хромогеном. После этого срезы докрашивали гематоксилином (1-3 мин) и заключали под покровное стекло. Результаты реакции учитывали с помощью микроскопа «Lеica DM 1000»: объектив HI PLAN 40×/0.65 $\infty / 0.17 / 0 F N 25$ с цифровой камерой высокого разрешения «Leica DMC 2900»; программное обеспечение «Leica Application Suite 8.0» (Leica; Германия). Суммарно было получено 1060 микрофотографий: 530 для UPARокрашенных стекол, 530 - для uРА-окрашенных.

\section{Обработка изображений}

В каждом изображении выбирали участок фона размерами $7 \times 7$ пикселей и присваивали ему среднее значение цвета всех пикселей, которые в нем содержатся. По данному цвету корректировали баланс белого так, чтобы полученный цвет становился белым. В результате на всех микрофотографиях цвет фона очень близок к белому, а цветовое пространство стало однородным. После этого в каждой фотографии вручную выделяли и удаляли крупные скопления эритроцитов и артефакты. Все изображения приводили к размеру 1024 × 768 пикселей.

\section{Измеряемые параметры}

В программе ImageJ, v1.51s (National Institutes of Health; США) для каждого изображения рассчитывали площадь ворсин (мм²) и площадь межворсинчатого пространства $\left(\mathrm{Mм}^{2}\right)$. При помощи выделения сосудов на микрофотографиях вручную оценивали площадь сосудов (\% от площади ворсин), стромально-сосудистое соотношение и интенсивность иммуногистохимической экспрессии UPA и UPAR ворсинами. Стромальнососудистое соотношение рассчитывали по формуле: площадь сосудов ворсин / (площадь ворсин - площадь сосудов ворсин). Все параметры вычисляли как геометрическое среднее показателей, полученных после обработки 10 изображений для каждого среза.

\section{Оценка интенсивности иммуногистохимической} экспрессии

В соответствующих ворсинам участках отбирали пиксели со значениями цвета в следующих диапазонах: hue [0;37], saturation [46;255], brightness [62;251]. Данные параметры позволяют определить большое количество оттенков коричневого цвета. Отобранные участки изображений переводили в черно-белый спектр для определения интенсивности окрашивания пикселей. Абсолютно черным пикселям присваивали значение 255, абсолютно белым - 0. Все пиксели, не входившие в состав ворсин, либо не отобранные по цветовому диапазону, также получили значение 0. Было посчитано среднее значение цвета пикселей в изображении без учета белых (со значением 0). Интенсивность экспрессии рассчитывали по формуле:

$$
\text { INT }=\frac{\sum_{c=0}^{255} C \times N_{c}}{V_{i} \times 1024 \times 768},
$$

где INT - интенсивность; с - среднее значение цвета не белых пикселей; $N$ - количество не белых пикселей на обработанном изображении; $V$ - доля площади изображения, занятая ворсинами, от 0 до 1. Результат расчета по указанной формуле можно интерпретировать как интенсивность экспрессии маркера от 0 (нет экспрессии) до 255 (максимальная экспрессия) в ворсине при условии ее равномерного окрашивания.

\section{Статистический анализ}

Статистический анализ выполняли с использованием программы RStudio v1.1.453 и веб-версии SNP Stats [10], разработанной для анализа исследований генетического полиморфизма генов. Информационный критерий Акаике (ИКА) использовали для определения модели наследования (кодоминантная, доминантная, рецессивная, 
сверхдоминантная или лог-аддитивная). Предпочтение отдавали моделям с наименьшими значениями ИКА, указывающими на хорошее соответствие данным при использовании меньшего числа параметров. Отличие распределения непрерывных переменных от нормального определяли при помощи теста Шапиро-Уилка. При сравнении групп в зависимости от вида распределения и числа групп использовали $t$-тест, тест Тьюки, однофакторный дисперсионный анализ, критерий суммы рангов Уилкоксона, критерий Краскела-Уоллиса. Категориальные переменные оценивали при помощи $\chi^{2}$-теста. В работе представляли также отношения шансов (ОШ) возникновения ПН. Для построения 95\%-х доверительных интервалов (ДИ) и точечной оценки ОШ применяли модель однофакторной бинарной логистической регрессии. Для исследования веса и статистической значимости отдельных генотипов использовали логистическую регрессию. Статистически достоверными считали результаты при $p<0,05$.

Таблица 1. Частота генотипов полиморфных вариантов генов урокиназной системы с доказанной для развития ПН значимостью

\begin{tabular}{|c|c|c|c|c|c|c|c|}
\hline & Модель наследования & Генотип & $\Pi \mathrm{H}, \%(n)$ & Контроль \% (n) & ОШ (ДИ95\%)* & $p$ & ИКА \\
\hline \multicolumn{8}{|c|}{ SNP матери } \\
\hline \multirow{10}{*}{ PLAU rs4065 } & \multirow{3}{*}{ Кодоминантная } & $\mathrm{C} / \mathrm{C}$ & $23,1(9)$ & $3,8(3)$ & $12,90(2,68-51,68)$ & \multirow{3}{*}{0,0001} & \multirow{3}{*}{120,9} \\
\hline & & $\mathrm{C} / \mathrm{T}$ & $41(16)$ & $21,8(17)$ & $5,46(1,94-15,37)$ & & \\
\hline & & $T / T$ & $35,9(14)$ & $74,4(58)$ & 1 & & \\
\hline & \multirow{2}{*}{ Доминантная } & $\mathrm{C} / \mathrm{T}-\mathrm{C} / \mathrm{C}$ & $64,1(25)$ & $25,6(20)$ & $6,83(2,63-17,79)$ & \multirow{2}{*}{$<0,0001$} & \multirow{2}{*}{120,1} \\
\hline & & $T / T$ & $35,9(14)$ & $74,4(58)$ & 1 & & \\
\hline & \multirow{2}{*}{ Рецессивная } & $\mathrm{C} / \mathrm{C}$ & $23,1(9)$ & $3,8(3)$ & $6,97(1,58-30,68)$ & \multirow{2}{*}{0,006} & \multirow{2}{*}{130} \\
\hline & & $\mathrm{T} / \mathrm{T}-\mathrm{C} / \mathrm{T}$ & $76,9(30)$ & $96,2(75)$ & 1 & & \\
\hline & \multirow{2}{*}{ Сверхдоминантная } & $\mathrm{C} / \mathrm{C}-\mathrm{T} / \mathrm{T}$ & $59(23)$ & $78,2(61)$ & 1 & \multirow{2}{*}{0,01} & \multirow{2}{*}{131} \\
\hline & & $\mathrm{C} / \mathrm{T}$ & $41(16)$ & $21,8(17)$ & $3,46(1,33-9,03)$ & & \\
\hline & Аддитивная & - & - & - & $4,14(2,02-8,51)$ & $<0,0001$ & 119,5 \\
\hline \multirow{10}{*}{ PLAUR rs2302524 } & \multirow{3}{*}{ Кодоминантная } & $A / A$ & $79,5(31)$ & $51,9(42)$ & 1 & \multirow{3}{*}{0,02} & \multirow{3}{*}{133,7} \\
\hline & & $A / G$ & $15,4(6)$ & $38,3(31)$ & $0,27(0,09-0,77)$ & & \\
\hline & & $\mathrm{G} / \mathrm{G}$ & $5,1(2)$ & $9,9(8)$ & $0,30(0,05-0,68)$ & & \\
\hline & \multirow{2}{*}{ Доминантная } & A/A & 79,5 (31) & $51,9(42)$ & 1 & \multirow{2}{*}{0,005} & \multirow{2}{*}{131,8} \\
\hline & & $\mathrm{A} / \mathrm{G}-\mathrm{G} / \mathrm{G}$ & 20,5 (8) & $48,1(39)$ & $0,27(0,1-0,71)$ & & \\
\hline & \multirow{2}{*}{ Рецессивная } & $\mathrm{A} / \mathrm{A}-\mathrm{A} / \mathrm{G}$ & $94,9(37)$ & $90,1(73)$ & 1 & \multirow{2}{*}{0,31} & \multirow{2}{*}{138,5} \\
\hline & & $\mathrm{G} / \mathrm{G}$ & $5,1(2)$ & $9,9(8)$ & $0,43(0,08-2,41)$ & & \\
\hline & & $\mathrm{A} / \mathrm{A}-\mathrm{G} / \mathrm{G}$ & $84,6(33)$ & $61,7(50)$ & 1 & 0010 & 121 \\
\hline & СверхдомИнанІная & $A / G$ & $15,4(6)$ & $38,3(31)$ & $0,31(0,11-0,87)$ & 0,018 & 134 \\
\hline & Аддитивная & - & - & - & $0,39(0,18-0,85)$ & 0,01 & 132,9 \\
\hline & & & SNP п & & & & \\
\hline & & $\mathrm{C} / \mathrm{C}$ & $30,9(17)$ & $4,3(1)$ & $8,25(0,88-77,21)$ & & \\
\hline & Кодоминантная & $\mathrm{C} / \mathrm{T}$ & $45,5(25)$ & $65,2(15)$ & $0,91(0,29-2,87)$ & 0,031 & 92,8 \\
\hline & & $T / T$ & 23,6 (13) & $30,4(7)$ & 1 & & \\
\hline & & $\mathrm{C} / \mathrm{T}-\mathrm{C} / \mathrm{C}$ & $76,4(42)$ & $69,6(16)$ & $1,37(0,45-4,17)$ & & \\
\hline & ДОМИнанІная & $\mathrm{T} / \mathrm{T}$ & $23,6(13)$ & $30,4(7)$ & 1 & 0,00 & 91,4 \\
\hline PLAU IS4UOS & Роивсоигиял & $\mathrm{C} / \mathrm{C}$ & $30,9(17)$ & $4,3(1)$ & $8,82(1,09-71,67)$ & Pח & 908 \\
\hline & гецессивная & $\mathrm{T} / \mathrm{T}-\mathrm{C} / \mathrm{T}$ & $69,1(38)$ & $95,7(22)$ & 1 & 0,009 & 90,0 \\
\hline & Conn & $\mathrm{C} / \mathrm{T}$ & $45,5(25)$ & $65,2(15)$ & $0,47(0,17-1,31)$ & 010 & 055 \\
\hline & Сверхдоминантная & $\mathrm{C} / \mathrm{C}-\mathrm{T} / \mathrm{T}$ & $54,5(30)$ & $34,8(8)$ & 1 & 0,14 & 95,5 \\
\hline & Аддитивная & - & - & - & $1,99(0,92-4,29)$ & 0,073 & 94,5 \\
\hline & & $T / T$ & $23,6(13)$ & $30,4(7)$ & 1 & & \\
\hline & Кодоминантная & $\mathrm{T} / \mathrm{C}$ & $45,5(25)$ & $65,2(15)$ & $0,28(0,11-0,71)$ & 0,014 & 117,9 \\
\hline & & $\mathrm{C} / \mathrm{C}$ & $30,9(17)$ & $4,3(1)$ & $2,71(0,53-13,76)$ & & \\
\hline & Поииночтия & $T / T$ & 23,6 (13) & $30,4(7)$ & 1 & 0,098 & 131,4 \\
\hline 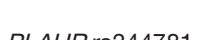 & дйvinanimar & $\mathrm{T} / \mathrm{C}-\mathrm{C} / \mathrm{C}$ & $76,4(42)$ & $69,6(16)$ & $0,49(0,21-1,16)$ & & \\
\hline 1 & 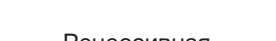 & $\mathrm{T} / \mathrm{T}-\mathrm{T} / \mathrm{C}$ & $69,1(38)$ & $95,7(22)$ & 1 & 0,018 & 128,5 \\
\hline & гецессивная & $\mathrm{C} / \mathrm{C}$ & $30,9(17)$ & 4,3 (1) & $5,02(1,07-23,6)$ & & \\
\hline & Сорияоиничти & $\mathrm{C} / \mathrm{C}-\mathrm{T} / \mathrm{T}$ & $54,5(30)$ & 34,8 (8) & 1 & $7 e-4$ & 122,7 \\
\hline & СверхдОМИНАнТная & $\mathrm{T} / \mathrm{C}$ & $45,5(25)$ & $65,2(15)$ & $0,22(0,09-0,54)$ & & \\
\hline & Аддитивная & - & - & - & $1,00(0,57-1,77)$ & 0,99 & 134,1 \\
\hline
\end{tabular}

Примечание: * — ОШ (95\% ДИ) с поправкой на возраст матери. 


\section{РЕЗУЛЬТАТЫ ИССЛЕДОВАНИЯ}

В табл. 1 представлены показатели частот полиморфных маркеров матери и новорожденного со статистически доказанной значимостью в отношении развития ПН с поправкой на возраст матери как фактор риска возникновения ПН. Полученные результаты свидетельствуют о наличии ассоциации между развитием $П Н$ и наличием у матери аллеля С гена PLAU rs4065, аллеля А гена PLAUR rs2302524, у новорожденного - аллеля C гена PLAU rs4065, аллеля C гена PLAUR rs344781. Для исследования совместного влияния генотипов матери и плода была построена модель, в которой зависимой переменной являлось наличие $П Н$, предикторами — генотипы матери и плода (наличие двух мутантных аллелей приравнивали к двум баллам, гетерозиготы - $\mathrm{k}$ одному, двух референсных - к нулю), далее оценивали статистическую значимость предикторов, их веса и влияние (положительное или отрицательное). Характеристики полученной модели представлены в табл. 2: достоверное влияние было подтверждено для rs4065 новорожденного замена C/T обладает протективным эффектом в отношении развития ПН, Т. е. уменьшает вероятность ее развития, наиболее прогностически благоприятным является наличие генотипа ТТ.

В контрольной группе обнаружено нормальное строение ворсинчатого древа: преобладание терминальных ворсин с синусоидально расширенными капиллярами, тесный контакт клеток трофобласта с подлежащей сосудистой стенкой. В группе ПН выявлено большое разнообразие гистопатологических феноменов. В ряде случаев наблюдали преобладание неразветвляющего ангиогенеза в виде дефицита терминальных ворсин, их малого диаметра, отсутствия синцитиальных почек. В 16 случаях выявлены выраженные компенсаторные реакции ткани плаценты: ангиоматоз ворсин, большое количество синцитиальных почек в сгруппированных терминальных ворсинах, сужение межворсинчатого пространства. Перечисленные различия подтверждает количественная оценка площади ворсин и площади межворсинчатого пространства (табл. 3). Различий между группами по показателю удельной площади сосудистого русла, стромально-сосудистому соотношению выявлено не было (табл. 3), что может быть вызвано гетерогенностью морфологической картины при преэклампсии и ЗРП, а также разными сроками родоразрешения.

Полученные при генотипировании матери и плода данные были соотнесены с результатами микроскопического исследования плаценты, в том числе морфометрии, и количественной оценкой иммуногистохимической экспрессии UPA и UPAR. Интенсивность иммуногистохимической экспрессии UPA и UPAR синцитиотрофобластом превосходила таковую стромы и клеток эндотелия сосудов ворсин (рис. 1А-Г). При сравнении групп по показателю иммуногистохимической экспрессии UРА интенсивность была достоверно ниже в ткани плацент пациенток с ПН $(p=0,033)$ (табл. 3; рис. 1А-Б), различий в экспрессии UPAR выявлено не было (табл. 3; рис. 1В-Г).

Ассоциации между наличием SNP в генах PLAU и PLAUR и интенсивностью экспрессии в ткани плаценты соответствующих белков обнаружено не было.

Протективное влияние замены C/T rs4065 у матери подтверждено взаимосвязью со степенью васкуляризации ворсин: в зависимости от генотипа удельная площадь сосудистого русла (доля от площади ворсин) и величина стромально-сосудистого соотношения были различными

Таблица 2. Параметры регрессионной модели, характеризующей зависимость риска развития ПН от наличия SNP в генах белков системы урокиназь

\begin{tabular}{|c|c|c|c|c|}
\hline & Коэффициенты факторов & Стандартная ошибка & z-значение & $p$ \\
\hline Свободный коэффициент & $-0,6347$ & 1,4248 & $-0,445$ & 0,656 \\
\hline \multicolumn{5}{|c|}{ SNP плода } \\
\hline PLAU rs2227564 & 4,0476 & 2,4788 & 1,778 & 0,075 \\
\hline SERPINE-1rs1799889 & 0,1157 & 1,2417 & 0,093 & 0,926 \\
\hline PLAU rs 4065 & $-3,3538$ & 1,3791 & $-2,432$ & 0,015 \\
\hline PLAUR rs344781 & 2,7448 & 1,5893 & 1,727 & 0,084 \\
\hline PLAUR rs2302524 & 0,3755 & 1,4117 & 0,266 & 0,79 \\
\hline \multicolumn{5}{|c|}{ SNP матери } \\
\hline PLAU rs2227564 & $-1,9485$ & 1,3233 & $-1,472$ & 0,141 \\
\hline SERPINE-1rs1799889 & $-2,276$ & 1,387 & $-1,641$ & 0,101 \\
\hline PLAU rs4065 & 1,8566 & 0,985 & 1,885 & 0,059 \\
\hline PLAUR rs344781 & $-0,7773$ & 1,3769 & $-0,564$ & 0,572 \\
\hline PLAUR rs2302524 & 2,0156 & 1,3489 & 1,494 & 0,135 \\
\hline
\end{tabular}

Таблица 3. Морфометрические характеристики и интенсивность иммуногистохимической экспрессии uPA/UPAR в ткани плаценты

\begin{tabular}{|l|c|c|}
\hline & \multicolumn{2}{|c|}{ Медиана (95\% дИ) } \\
\hline & ПН Контроль \\
\hline Площадь ворсин (мм²) & $7,445(6,852 ; 7,863)$ & $6,464(6,213 ; 7,157)$ \\
\hline Площадь межворсинчатого пространства (мм²) & $6,621(6,22 ; 7,17)$ & $7,611(6,887 ; 7,84)$ \\
\hline Площадь сосудов ворсин (\% от площади ворсин) & $19,55(16,45 ; 24,85)$ & $18,2(14,2 ; 22,6)$ \\
\hline Стромально-сосудистое соотношение & $0,206(0,166 ; 0,26)$ & $0,178(0,147 ; 0,253)$ \\
\hline Экспрессия иРА & $116,449(100,496 ; 128,74)$ & $126,087(113,761 ; 139,191)$ \\
\hline Экспрессия UРАR & $117,59(96,24 ; 138,94)$ & $130,42(107,93 ; 152,91)$ \\
\hline
\end{tabular}


(рис. 2). Площадь сосудистого русла и величина стромальнососудистого соотношения достигали наибольших значений при генотипе ТТ (табл. 4).

\section{ОБСУЖДЕНИЕ РЕЗУЛЬТАТОВ}

Система URA-uPAR многофункциональна. Наряду с фибринолитической активностью и участием в деградации внеклеточного матрикса она определяет доступность ростовых факторов, влияет на процессы миграции и пролиферации клеток. С момента имплантации эмбриона возрастает синтез урокиназы клетками трофобласта [11], повышается экспрессия UPAR на полюсе клетки, осуществляющем инвазию, параллельно активность UPA контролируют ингибиторы PAI-1,2. Таким образом, при активном участии урокиназной системы идет процесс модулируемой инвазии клеток тросробласта. Кроме клеток трофобласта источниками UPA в плаценте являются NKклетки и макрофаги. С трофобласт-независимых стадий они обеспечивают ремоделирование спиральных артерий эндометрия, и только в ассоциации с ними uPAR-позитивные гладкомышечные и эндотелиальные клетки приобретают миграционный фенотип [12, 13]. Под контролем урокиназной системы, а именно экспрессирующих данные белки клеток, находится и процесс образования и деградации фибриноида фибринового типа [14]. Протеолиз внеклеточного матрикса, в том числе сериновыми протеазами, приводит к высвобождению из его скаффролда ангиогенных факторов, включая фрактор роста эндотелия сосудов (VEGF). Взаимодействие VEGF с его рецептором 2 класса в свою очередь приводит к экспонированию протеолитического комплекса UPA-UPAR с интегринами [15], что подтверждает роль урокиназной системы как посредника эффектов ангиогенных факторов и участника ангиогенеза, в том числе и в плаценте.

В ходе нашей попытки оценить риск развития плацентоассоциированных осложнений беременности в зависимости от наличия однонуклеотидных замен в генах матери и плода было показано, что наиболее низкому риску развития ПН соответствует ТТ генотип PLAU rs4065.
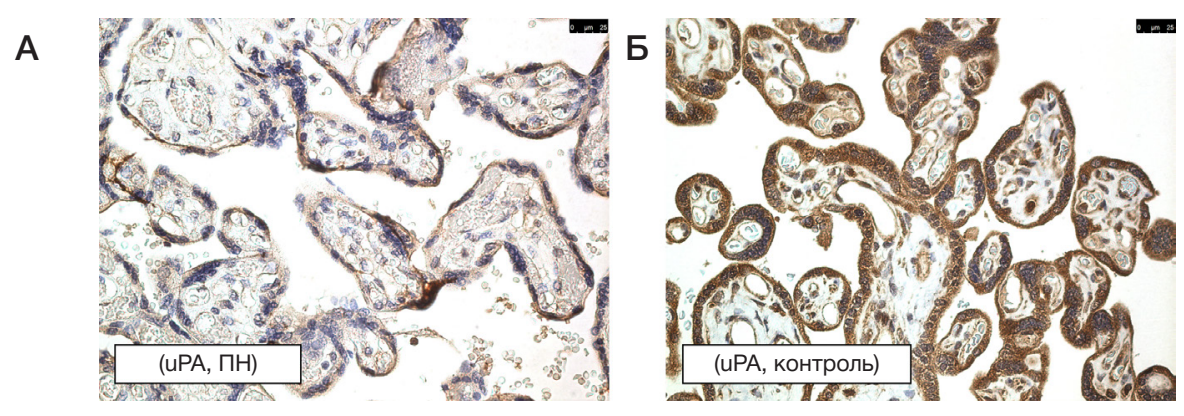

B
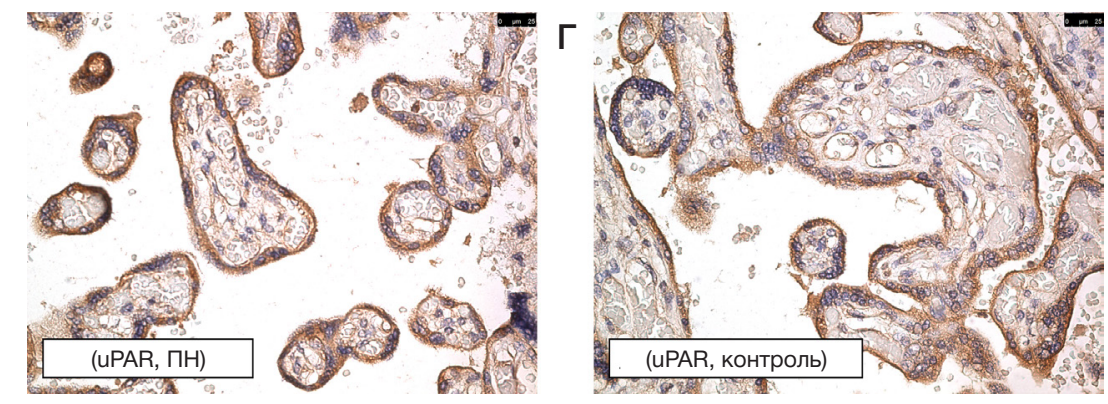

Рис. 1. Экспрессия UPA (А, Б) и UPAR (В, Г) ворсинами хориона в контрольной группе (А, В) и группе ПН (Б, Г) при иммуногистохимическом выявлении. В норме и при ПН отмечают интенсивное окрашивание синцитиотрофобласта антителами к uРА и UРАR (A-Г). В ткани плаценты при ПН (А) выявлено менее интенсивное иРА-окрашивание синцитиотрофобласта по сравнению с контрольной группой (Б). Разницы в экспрессии иРАR при ее иммуногистохимической оценке между группами выявлено не было (В, Г). Масштабная линейка - 25 мкм
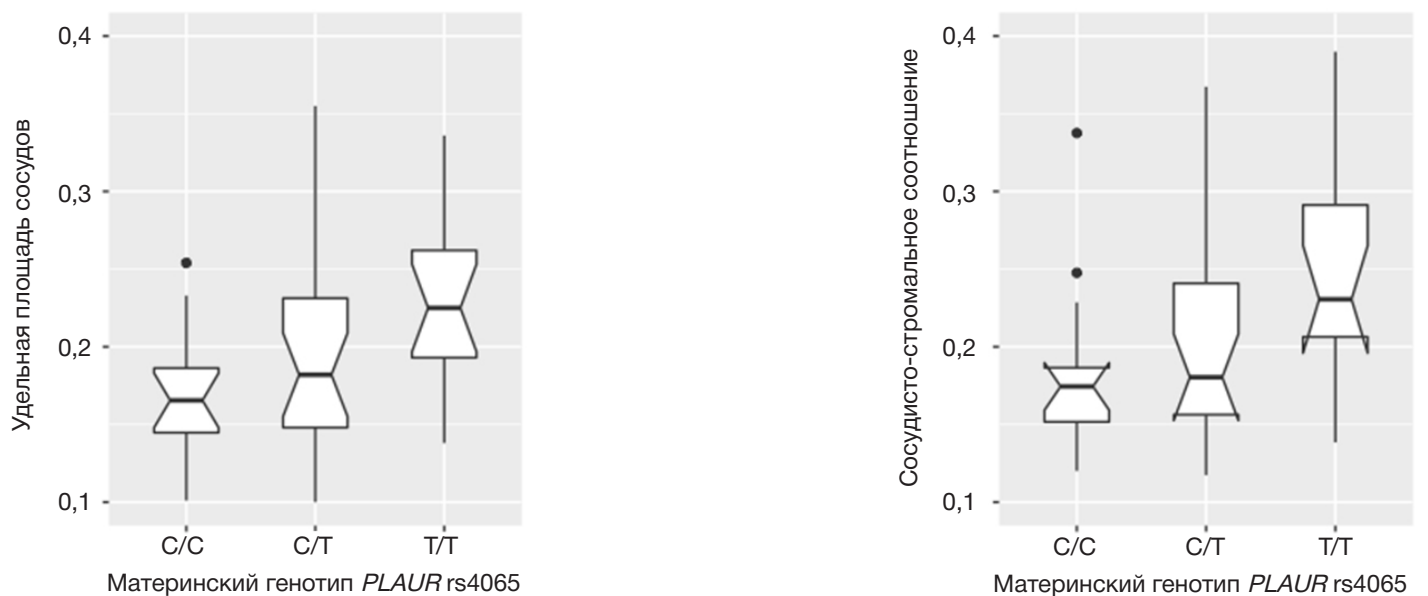

Рис. 2. Удельная площадь сосудистого русла ворсин и стромально-сосудистое соотношение в зависимости от генотипа матери по PLAU rs4065. Границами ящика служат первый и третий квартили, линия в середине ящика - медиана. Концы усов - разность первого квартиля и полутора межквартильных расстояний; сумма третьего квартиля и полутора межквартильных расстояний. Выбросы отображаются на графике в виде точек. Зарубками обозначены доверительные интервалы для медиань 
Таблица 4. Площадь сосудистого русла и стромально-сосудистое соотношение в зависимости от генотипа матери по rs4065 PLAU

\begin{tabular}{|c|c|c|c|c|c|c|}
\hline \multirow{2}{*}{ Генотип по rs 4065} & \multicolumn{3}{|c|}{ Площадь сосудистого русла, мм² } & \multicolumn{3}{|c|}{ Стромально-сосудистое соотношение } \\
\hline & Медиана & 95\% ди & $p^{\star \star}$ & Медиана & $95 \%$ ди & $p^{\star \star}$ \\
\hline $\mathrm{CC}$ & 0,1655 & {$[0,1461 ; 0,1849]$} & \multirow{3}{*}{0,0305} & 0,1715 & {$[0,1524 ; 0,1907]$} & \multirow{3}{*}{0,0265} \\
\hline CT & 0,182 & {$[0,1528 ; 0,2112]$} & & 0,1804 & {$[0,1485 ; 0,2123]$} & \\
\hline$\pi$ & 0,225 & {$[0,1969 ; 0,2531]$} & & 0,2306 & {$[0,1959 ; 0,2652]$} & \\
\hline
\end{tabular}

Примечание: ** — сравнение с использованием критерия Краскела-Уоллиса.

Учитывая, что в большинстве случаев, генотип плаценты совпадает с генотипом плода, закономерным было определить наличие аллеля $\mathrm{T}$ у плода как более значимого. K сожалению, нам не удалось доказать, что изменения уровня UРА в плаценте обусловлены наличием исследованных однонуклеотидных замен в ее гене, что может быть обусловлено небольшим количеством изученных образцов. Однако ассоциация генотипа ТТ с большей площадью сосудистого компонента ворсин подтверждает выявленный при оценке риска развития ПН феномен.

Ранее было продемонстрировано, что экспрессия UPAR ворсинами хориона у пациенток с нормально протекающей беременностью выше, чем у тех, чья беременность осложнена угрозой ее прерывания [16]. В нашем исследовании уровни UPAR при иммуногистохимической оценке экспрессии белка не отличались в норме и у пациенток с плацентоассоциированными осложнениями беременности, однако были выявлены различия при сравнении групп по интенсивности экспрессии самой урокиназы.

Влияние rs4065 SNP напрямую на уровень экспрессии UPA не было доказано ранее. По полученным нами результатам можно предположить, что наличие генотипа
ПТ усиливает процессы миграции и пролисерации клеток, носит проангиогенный характер, снижая риск развития ПН. Данный факт подтверждает влияние этого полиморсизма на опухолевую прогрессию и аналогичное потенциирование опухолевого ангиогенеза. Существуют данные о значительном увеличении риска развития злокачественных новообразований при наличии аллеля Т и генотипа ТТ [17-19]. В то же время общепринят фракт, что высокий уровень UРА в ткани ряда опухолей служит предпосылкой неблагоприятного исхода [20]. Кроме того, Т-аллель rs4065 связан с развитием синдрома Квебека состояния, обусловленного избыточным фибринолизом вследствие повышенного содержания uРА в тромбоцитах [21].

\section{ВЫВОДЫ}

Высокий уровень uРА в плаценте и наличие генотипа ПТ у плода по rs4065 гена uPA носят протективный характер в отношении развития ПН. Мы предполагаем, что результаты проведенного исследования позволят расширить возможности неинвазивной пренатальной диагностики и прогнозировать развитие ПН путем генотипирования фетальной ДНК по rs4065 PLAU.

\section{Литература}

1. Benirschke K, Burton GJ, Baergen RN. Pathology of the Human Placenta, 6th ed. Springer, 2012; p. 411.

2. Poettler M, Unseld M, Mihaly-Bison J, Uhrin P, Koban F. Binder BR, et al. The urokinase receptor (CD87) represents a central mediator of growth factor-induced endothelial cell migration. Thromb Haemost. 2012; 108 (8): 357-66.

3. Tkachuk VA, Plekhanova OS, Parfyonova YV. Regulation of arterial remodeling and angiogenesis by urokinase-type plasminogen activator. Can J Physiol Pharmacol. 2009; 87 (4): 231-51.

4. Khosravi F, Zarei S, Ahmadvand N, Akbarzadeh-Pasha Z, Savadi E, Zarnani $\mathrm{A}$, et al. Association between plasminogen activator inhibitor 1 gene mutation and different subgroups of recurrent miscarriage and implantation failure. J Assist Reprod Genet. 2014; 31 (1): 121-4.

5. Zhao L, Bracken MB, DeWan AT, Chen S. Association between the SERPINE1 (PAI-1) 4G/5G insertion/deletion promoter polymorphism (rs1799889) and pre-eclampsia: A systematic review and meta-analysis. Molecular Human Reproduction. 2013; 19 (3): 136-43.

6. Tran $\mathrm{H}$, Maurer F, Nagamine Y. Stabilization of urokinase and urokinase receptor mRNAs by HuR is linked to its cytoplasmic accumulation induced by activated mitogen-activated protein kinase-activated protein kinase 2. Mol Cell Biol. 2003; 23 (20): 7177-88.

7. Xu J, Li W, Bao X, Ding H, Chen J, Zhang W, et al. Association of putative functional variants in the PLAU gene and the PLAUR gene with myocardial infarction. Clin Sci (Lond). 2010; 119 (8): 353-9.

8. Yosrlimoto M, Youichi, Ushiyama Y, Sakaia M, Tamakia S, Hara H, et al. Characterization of single chain urokinase-type plasminogen activator with a novel amino-acid substitution in the kringle structure. Biochimica et Biophysica Acta (BBA)-Protein Structure and Molecular Enzymology. 1996; 1293 (1): 83-9.

9. Campbell DB, Li C, Sutcliffe JS, Persico AM, Levitt P. Genetic evidence implicating multiple genes in the met receptor tyrosine kinase pathway in autism spectrum disorder. Autism Res. 2008; 1 (3): 159-68.

10. Solé X, Guinó E, Valls J, Iniesta R, Moreno V. SNPStats: a web tool for the analysis of association studies. Bioinformatics. 2006 22 (15): 1928-29.

11. Martínez-Hernández MG, Baiza-Gutman LA, Castillo-Trápala A Armant DR. Regulation of proteinases during mouse periimplantation development: Urokinase-type plasminogen activator expression and cross talk with matrix metalloproteinase 9 . Reproduction. 2011; 141 (2): 227.

12. Lash GE, Otun HA, Innes BA, Percival K, Searle RF, Robson SC, et al. Regulation of extravillous trophoblast invasion by uterine natural killer cells is dependent on gestational age. Hum Reprod. 2010; 25 (5): 1137-45

13. Naruse K, Lash GE, Bulmer JN, Innes BA, Otun HA, Searle RF, et al. The Urokinase Plasminogen Activator (UPA) System in Uterine Natural Killer Cells in the Placental Bed During Early Pregnancy. Placenta. 2009; 30 (5): 398-404.

14. Pierleoni C, Castellucci M, Kaufmann P, Lund LR, Schnack Nielsen B, Urokinase receptor is up-regulated in endothelial cells and macrophages associated with fibrinoid deposits in the human placenta. Placenta. 2003; 24 (6): 677-85.

15. Breuss JM, Uhrin P. VEGF-initiated angiogenesis and the UPA uPAR system. Cell adhesion \& migration. 2012; 6 (6): 535-40.

16. Liu S, Zheng Q, Cui XY, Dai KX, Yang XS, Li FS, et al. Expression 
of UPAR in human trophoblast and its role in trophoblast invasion. Int J Clin Exp Pathol [Internet]. e-Century Publishing Corporation; 2015; 8 (11): 14325-34. Available from: https://www.ncbi.nlm. nih.gov/pmc/articles/PMC4713534/.

17. Xu Z, Meng L-L, Lin J, Ling Y, Chen S, Lin N. Association between the polymorphisms of urokinase plasminogen activation system and cancer risk: a meta-analysis. Onco Targets Ther [Internet]. Dove Medical Press. 2015; 9 (8): 2493-502. Available from: http://www.ncbi.nlm.nih.gov/pmc/articles/PMC4574847/.

18. Andreasen P, Kjøller L, Christensen L, Duffy MJ. The urokinasetype plasminogen activator system in cancer metastasis: a review.

\section{References}

1. Benirschke K, Burton GJ, Baergen RN. Pathology of the Human Placenta, 6th ed. Springer, 2012; p. 411.

2. Poettler M, Unseld M, Mihaly-Bison J, Uhrin P, Koban F. Binder BR, et al. The urokinase receptor (CD87) represents a central mediator of growth factor-induced endothelial cell migration. Thromb Haemost. 2012; 108 (8): 357-66.

3. Tkachuk VA, Plekhanova OS, Parfyonova YV. Regulation of arterial remodeling and angiogenesis by urokinase-type plasminogen activator. Can J Physiol Pharmacol. 2009; 87 (4): 231-51.

4. Khosravi F, Zarei S, Ahmadvand N, Akbarzadeh-Pasha Z, Savadi E, Zarnani $A$, et al. Association between plasminogen activator inhibitor 1 gene mutation and different subgroups of recurrent miscarriage and implantation failure. J Assist Reprod Genet. 2014; 31 (1): 121-4

5. Zhao L, Bracken MB, DeWan AT, Chen S. Association between the SERPINE1 (PAI-1) 4G/5G insertion/deletion promoter polymorphism (rs1799889) and pre-eclampsia: A systematic review and meta-analysis. Molecular Human Reproduction. 2013; 19 (3): 136-43.

6. Tran $H$, Maurer $F$, Nagamine $Y$. Stabilization of urokinase and urokinase receptor mRNAs by HuR is linked to its cytoplasmic accumulation induced by activated mitogen-activated protein kinase-activated protein kinase 2. Mol Cell Biol. 2003; 23 (20): 7177-88.

7. Xu J, Li W, Bao X, Ding H, Chen J, Zhang W, et al. Association of putative functional variants in the PLAU gene and the PLAUR gene with myocardial infarction. Clin Sci (Lond). 2010; 119 (8): 353-9.

8. Yosrlimoto M, Youichi, Ushiyama Y, Sakaia M, Tamakia S, Hara H, et al. Characterization of single chain urokinase-type plasminogen activator with a novel amino-acid substitution in the kringle structure. Biochimica et Biophysica Acta (BBA)-Protein Structure and Molecular Enzymology. 1996; 1293 (1): 83-9.

9. Campbell DB, Li C, Sutcliffe JS, Persico AM, Levitt P. Genetic evidence implicating multiple genes in the met receptor tyrosine kinase pathway in autism spectrum disorder. Autism Res. 2008; 1 (3): 159-68

10. Solé X, Guinó E, Valls J, Iniesta R, Moreno V. SNPStats: a web tool for the analysis of association studies. Bioinformatics. 2006; 22 (15): 1928-29.

11. Martínez-Hernández MG, Baiza-Gutman LA, Castillo-Trápala A,
Int J Cancer. 1997; 72 (1): 1-22.

19. Duffy MJ, Maguire TM, McDermott EW, O'Higgins N. Urokinase plasminogen activator: a prognostic marker in multiple types of cancer. J Surg Oncol. 1999; 71 (2): 130-5.

20. Fuhrman B. The urokinase system in the pathogenesis of atherosclerosis. Atherosclerosis. Ireland; 2012 May; 222 (1): 8-14.

21. Diamandis M, Paterson AD, Rommens JM, Veljkovic DK, Blavignac J, Bulman DE, et al. Quebec platelet disorder is linked to the urokinase plasminogen activator gene (PLAU) and increases expression of the linked allele in megakaryocytes. Blood. 2009; 113 (7): 1543-6.

Armant DR. Regulation of proteinases during mouse periimplantation development: Urokinase-type plasminogen activator expression and cross talk with matrix metalloproteinase 9. Reproduction. 2011; 141 (2): 227.

12. Lash GE, Otun HA, Innes BA, Percival K, Searle RF, Robson SC, et al. Regulation of extravillous trophoblast invasion by uterine natural killer cells is dependent on gestational age. Hum Reprod. 2010; 25 (5): 1137-45.

13. Naruse K, Lash GE, Bulmer JN, Innes BA, Otun HA, Searle RF, et al. The Urokinase Plasminogen Activator (UPA) System in Uterine Natural Killer Cells in the Placental Bed During Early Pregnancy. Placenta. 2009; 30 (5): 398-404.

14. Pierleoni C, Castellucci M, Kaufmann P, Lund LR, Schnack Nielsen B, Urokinase receptor is up-regulated in endothelial cells and macrophages associated with fibrinoid deposits in the human placenta. Placenta. 2003; 24 (6): 677-85.

15. Breuss JM, Uhrin P. VEGF-initiated angiogenesis and the UPA uPAR system. Cell adhesion \& migration. 2012; 6 (6): 535-40.

16. Liu S, Zheng Q, Cui XY, Dai KX, Yang XS, Li FS, et al. Expression of UPAR in human trophoblast and its role in trophoblast invasion. Int J Clin Exp Pathol [Internet]. e-Century Publishing Corporation; 2015; 8 (11): 14325-34. Available from: https://www.ncbi.nIm. nih.gov/pmc/articles/PMC4713534/.

17. Xu Z, Meng L-L, Lin J, Ling Y, Chen S, Lin N. Association between the polymorphisms of urokinase plasminogen activation system and cancer risk: a meta-analysis. Onco Targets Ther [Internet]. Dove Medical Press. 2015; 9 (8): 2493-502. Available from: http://www.ncbi.nlm.nih.gov/pmc/articles/PMC4574847/.

18. Andreasen P, Kjøller L, Christensen L, Duffy MJ. The urokinasetype plasminogen activator system in cancer metastasis: a review. Int J Cancer. 1997; 72 (1): 1-22.

19. Duffy MJ, Maguire TM, McDermott EW, O'Higgins N. Urokinase plasminogen activator: a prognostic marker in multiple types of cancer. J Surg Oncol. 1999; 71 (2): 130-5.

20. Fuhrman B. The urokinase system in the pathogenesis of atherosclerosis. Atherosclerosis. Ireland; 2012 May; 222 (1): 8-14.

21. Diamandis $M$, Paterson AD, Rommens JM, Veljkovic DK Blavignac J, Bulman DE, et al. Quebec platelet disorder is linked to the urokinase plasminogen activator gene (PLAU) and increases expression of the linked allele in megakaryocytes. Blood. 2009; $113(7): 1543-6$. 